\title{
Image-based 3D Nanocrystallography by Means of Tilt Protocol/Lattice-Fringe Fingerprinting with Contemporary Side-entry Specimen Goniometers
}

\author{
Peter Moeck*, Bjoern Seipel*, Wentao Qin**, Eric Mandell***, and Philip Fraundorf*** \\ * Department of Physics, Portland State University, P.O. Box 751, Portland, OR 97207-0751 \\ ** Technology Solutions, Freescale Semiconductor Inc., MD CH305, Chandler, AZ 85224 \\ *** Department of Physics and Astronomy and Center for Molecular Electronics, University of \\ Missouri at St. Louis, MO 53121
}

The feasibility of discrete atomic resolution electron tomography by means of exit-wave reconstruction in future aberration-corrected transmission electron microscopes (TEM) has recently been demonstrated for individual crystalline nanoparticles [1]. While fully eucentric highly precise specimen goniometers will be required for that novel technique to reach its full potential, imagebased 3D nanocrystallography by means of tilt protocol/lattice-fringe fingerprinting can already be practiced with the current generations of TEMs and side-entry specimen goniometers. A Philips EM430 ST microscope equipped with a double-tilt goniometer that allows for $\pm 15^{\circ}$ eucentric tilt and $\pm 10^{\circ}$ non-eucentric tilt was, for example, used to determine the lattice parameters of substoichiometric $\mathrm{WC}_{1-\mathrm{x}}$ nanocrystals with the rock salt structure [2,3]. Due to this relatively small tilt range, only the so called "cubic minimalistic" tilt protocol, which requires a combined tilt of $35.3^{\circ}$ about an effective $<110>$ tilt axis that coincides with the eucentric axis of the specimen goniometer, could be employed. The angular tilt range (i.e. accessible region of orientation space) of a $\pm 20^{\circ}$ tilt $360^{\circ}$ rotation goniometer is nine times larger that that of a $\pm 20^{\circ}$ double-tilt goniometer. $\mathrm{A} \pm 20^{\circ}$ double-tilt $360^{\circ}$ rotation goniometer, on the other hand, possesses in addition to the approximately 1.4 times larger tilt range of the above mentioned tilt rotation goniometer the advantage of an extra degree of freedom to tilt an assembly of crystalline nanoparticles. This allows for concepts from classical crystallometry [4] to be applied to image-based 3D nanocrystallography [5]. This extra degree of freedom also allows for the alignment of the effective tilt axis of any tilt protocol parallel to the eucentric axis of the specimen goniometer. This alignment can be done in small angular increments so that a novel type of discrete atomic resolution electron tomography for an ensemble of crystalline nanoparticles can be practiced. The instrumental parameters for the applicability of this novel technique are directly interpretable resolution and available tilt range. Table 1 gives these parameters for a variety of existing and future aberration-corrected TEMs together with a measure for the viability of our new technique. We take as a measure for viability simply the number of different tilt protocols that are possible for the above mentioned $\mathrm{WC}_{1-\mathrm{x}}$ nanocrystals. It is clear from this table that our method is practicable with currently existing equipment and will become much more viable in future aberration-corrected TEMs.

References

[1] J. R. Jinschek et al., Mat. Res. Soc. Symp. Proc. 839 (2005) P4.5.1.

[2] W. Qin and P. Fraundorf, Ultramicroscopy 94 (2003) 245.

[3] P. Fraundorf et al., arXiv:cond-mat/0212281v2 (2005).

[4] P. Terpstra and L.W. Godd, Crystallometry, Academic Press, New York, 1961.

[5] P. Moeck et al., Mat. Res. Soc. Symp. Proc. 839 (2005) P4.3.1 and 818 (2004) M11.3.1.

[6] This work was supported by a grant from Research Corporation and benefited indirectly from support by the US Department of Energy, the Missouri Research Board, as well as Monsanto and MEMC electronic materials companies. 
TABLE 1. Parameters of current and future aberration-corrected TEMs for image-based 3D nanocrystallography by means of tilt protocol/lattice-fringe fingerprinting. The visible lattice fringe types and zone axes of $\mathrm{WC}_{1-x}$ nanocrystals for these parameters are also given. The number of possible tilt protocols - as given in the last column - may be considered as a measure of the viability of our novel discrete atomic resolution electron tomography technique for an ensemble of nanocrystals.

\begin{tabular}{|c|c|c|c|c|c|c|c|}
\hline \begin{tabular}{|l|} 
Spherical \\
aberration \\
coefficient, \\
C s, of \\
objective lens \\
[cm], \\
(prototypes, \\
kV)
\end{tabular} & \begin{tabular}{|l} 
Directly \\
interpretable \\
(electron \\
phase \\
contrast, \\
Scherzer) \\
point to point \\
resolution (x) \\
[nm]
\end{tabular} & \begin{tabular}{|l} 
Relative \\
resolution \\
improvement \\
RRI $(x)=(1-$ \\
x/0.24 nm) $100 \%$ \\
(i.e. with \\
respect to \\
Tecnai G T2 $^{2}$ F \\
SuperTwin)
\end{tabular} & \begin{tabular}{|l|} 
Visible lattice \\
fringe types* \\
\& zone axes, \\
i.e. lattice \\
fringe \\
crossings, \\
within one \\
stereographic \\
triangle [001]- \\
[011]-[111]
\end{tabular} & $\begin{array}{l}\text { Average } \\
\text { angle } \\
\text { between } \\
\text { visible zone } \\
\text { axes }\end{array}$ & \begin{tabular}{|l} 
Minimum \\
double-tilt \\
range \\
requirement \\
to achieve \\
average angle \\
between \\
visible zone \\
axes
\end{tabular} & $\begin{array}{l}\text { Tilt range of a } \\
\text { Gatan Model } \\
925 \text { double-tilt } \\
\text { rotation } \\
\text { goniometer** }\end{array}$ & $\begin{array}{l}\text { Number and } \\
\text { type of tilt } \\
\text { protocols } \\
\text { (i.e. a simple } \\
\text { measure for } \\
\text { the feasibility } \\
\text { of our novel } \\
\text { electron } \\
\text { tomography } \\
\text { method) }\end{array}$ \\
\hline $\begin{array}{l}1.2 \\
\text { (Tecnai G² F20 } \\
\text { SuperTwin, } \\
200 \mathrm{kV} \text { ) } \\
\end{array}$ & 0.24 & $0 \%$ & $\begin{array}{l}\{111\} \& \\
{[011]}\end{array}$ & $60^{\circ}$ & $\pm 22.5^{\circ}$ & $\begin{array}{l} \pm 30^{\circ} \\
\text { eucentric tilt, } \pm \\
18^{\circ} \text { non- } \\
\text { eucentric tilt }\end{array}$ & $\begin{array}{l}\text { one [011]- } \\
{[110] \text { tilt }} \\
\text { protocol }\end{array}$ \\
\hline $\begin{array}{l}1.2 \\
\text { (Philips EM430 } \\
\text { SuperTwin, } \\
(300 \mathrm{kV})\end{array}$ & 0.19 & $\approx 21 \%$ & $\begin{array}{l}\{111\},\{200\} \& \\
{[001],[011]}\end{array}$ & $\begin{array}{l}50^{\circ} \text { (out of the } \\
3 \text { pairs in two } \\
\text { stereographic } \\
\text { triangles, } \\
{[001]-[011]-} \\
{[111]-[101] \text { ) }} \\
\end{array}$ & $\pm 18.4^{\circ}$ & $\begin{array}{l} \pm 25^{\circ} \\
\text { eucentric tilt, } \pm \\
15^{\circ} \text { non- } \\
\text { eucentric tilt }\end{array}$ & $\begin{array}{l}\text { two [001]- } \\
<110>\text { and the } \\
m c^{\star * * \star} \text { tilt } \\
\text { protocol }\end{array}$ \\
\hline $\begin{array}{l}0.5 \\
\text { (Tecnai G2 F20 } \\
\text { UltraTwin, } 200 \\
\text { kV) }\end{array}$ & 0.19 & $\approx 21 \%$ & $\begin{array}{l}\{111\},\{200\} \& \\
{[001],[011]}\end{array}$ & $\begin{array}{l}50^{\circ} \text { (out of the } \\
3 \text { pairs in two } \\
\text { stereographic } \\
\text { triangles, } \\
{[001]-[011]-} \\
{[111]-[101] \text { ) }} \\
\end{array}$ & $\pm 18.4^{\circ}$ & $\begin{array}{l} \pm 15^{\circ} \text { for both } \\
\text { eucentric and } \\
\text { non-eucentric } \\
\text { tilts }\end{array}$ & $\begin{array}{l}\text { the } \mathrm{mc}^{\star \star \star \star} \\
\text { protocol }\end{array}$ \\
\hline \begin{tabular}{|l|}
$\approx 0$ \\
(Cs -corrected \\
Tecnai G2 F20 \\
SuperTwin, \\
$200 \mathrm{kV})$ \\
\end{tabular} & $\begin{array}{l}0.12 \\
\text { (approaching } \\
\text { the information } \\
\text { limit) }\end{array}$ & $50 \%$ & $\begin{array}{l}\{111\},\{200\}, \\
\{220\},\{311\} \& \\
{[001],[011],} \\
{[111],[112],} \\
{[013],[114],} \\
{[233],[125]}\end{array}$ & $\begin{array}{l}18.2^{\circ} \text { (out of } \\
\text { the } 14 \text { pairs in } \\
\text { one } \\
\text { stereographic } \\
\text { triangle) }\end{array}$ & $\pm 6.5^{\circ}$ & $\begin{array}{l} \pm 30^{\circ} \\
\text { eucentric tilt, } \pm \\
18^{\circ} \text { non- } \\
\text { eucentric tilt }\end{array}$ & $\begin{array}{l}28 \text { different tilt } \\
\text { protocols }\end{array}$ \\
\hline $\begin{array}{l}\approx 0 \\
\text { (Cs and } \\
\text { possibly also } \\
\text { chromatic } \\
\text { aberration- } \\
\text { corrected } \\
\text { TEAM } \\
\text { project } \\
\text { microscopes, } \\
200-300 \mathrm{kV} \text { ) }\end{array}$ & $\leq 0.06$ & $\geq 75 \%$ & $\begin{array}{l}\geq 12 \text { lattice } \\
\text { fringe types, } \\
\text { e.g. }\{111\}, \\
\{200\},\{220\}, \\
\{311\},\{331\}, \\
\{420\},\{422\}, \\
\{511\},\{531\}, \\
\{442\},\{620\}, \\
\{622\}, \ldots \\
\text { resulting in } \geq \\
2^{4} \text { zone axes } \\
\text { with }[u+v+\text { w] } \\
\leq 8 \\
\end{array}$ & $\begin{array}{l}\leq 9.3^{\circ} \text { (out of } \\
\text { the } 21 \text { pairs of } \\
\text { zone axes with } \\
{[u+v+w] \leq 8} \\
\text { in one } \\
\text { stereographic } \\
\text { triangle that } \\
\text { are along } \\
\{111\},\{200\}, \\
\text { and }\{220\} \\
\text { bands }\end{array}$ & $\begin{array}{l}\leq \pm 3.3^{\circ} \text { (when } \\
\text { aiming only for } \\
\text { those zone } \\
\text { axes with }[u+ \\
v+w] \leq 8 \text { that } \\
\text { are along } \\
\{111\},\{200\}, \\
\text { and }\{220\} \\
\text { bands }\end{array}$ & $\begin{array}{l}\text { no } \\
\text { specification, } \\
\text { but there could } \\
\text { be space in the } \\
\mathrm{cm} \text { range in all } \\
3 \text { dimensions } \\
\text { to construct } \\
\text { fully } \\
\text { (compucentric) } \\
\text { goniometers } \\
\text { with } 3 \text { degrees } \\
\text { of freedom to } \\
\text { tilt and rotate } \\
\end{array}$ & $\begin{array}{l}21 \text { different tilt } \\
\text { protocols } \\
\text { (when only } \\
\text { aiming for } \\
\text { those zone- } \\
\text { axis pairs } \\
\text { mentioned in } \\
\text { rows } 5 \text { and 6), } \\
\text { more than } 50 \\
\text { different tilt } \\
\text { protocols } \\
\text { without this } \\
\text { restriction } \\
\end{array}$ \\
\hline
\end{tabular}

* Different types of lattice fringes have different crystallographic multiplicities; ${ }^{* *}$ as communicated to us by Gatan Inc. in January $2005 ;{ }^{* * *}$ note also that the wider the difference between the maximal combined tilt range and the required tilt for a certain tilt protocol is, the more orientation space can be assessed; **** mc stands for "minimalistic cubic", i.e. from $<001>$ as revealed by crossed $\{020\}$ fringes to $<112>$ as revealed by a single set of \{111\} fringes, see refs. [2-3] and [5]; ${ }^{* * \star * *}$ TEAM stands for Transmission Electron Aberration-corrected Microscope, http://ncem.lbl.gov/team3.htm. 